Article

\title{
Dependence on Film Thickness of Guest-Induced $c$ Perpendicular Orientation in PPO Films
}

\author{
Baku Nagendra, Emanuele Vignola, Christophe Daniel (D), Paola Rizzo (D) and Gaetano Guerra* \\ Dipartimento di Chimica e Biologia, INSTM Research Unit, Università di Salerno, Via Giovanni Paolo II 132, \\ 84084 Fisciano, Italy; bakunagendra@gmail.com (B.N.); evignola@unisa.it (E.V.); cdaniel@unisa.it (C.D.); \\ prizzo@unisa.it (P.R.) \\ * Correspondence: gguerra@unisa.it
}

Citation: Nagendra, B.; Vignola, E.; Daniel, C.; Rizzo, P.; Guerra, G. Dependence on Film Thickness of Guest-Induced $c$ Perpendicular Orientation in PPO Films. Polymers 2021, 13, 4384. https://doi.org/ $10.3390 /$ polym 13244384

Academic Editors: Rufina G. Alamo, Günter Reiter and Jun Xu

Received: 4 November 2021 Accepted: 10 December 2021 Published: 14 December 2021

Publisher's Note: MDPI stays neutral with regard to jurisdictional claims in published maps and institutional affiliations.

Copyright: (c) 2021 by the authors. Licensee MDPI, Basel, Switzerland. This article is an open access article distributed under the terms and conditions of the Creative Commons Attribution (CC BY) license (https:// creativecommons.org/licenses/by/ $4.0 /)$.

\begin{abstract}
For poly(2,6-dimethyl-1,4-phenylene)oxide (PPO) films exhibiting nanoporous-crystalline (NC) phases, $c_{\perp}$ orientation (i.e., crystalline polymer chain axes being preferentially perpendicular to the film plane) is obtained by crystallization of amorphous films, as induced by sorption of suitable low-molecular-mass guest molecules. The occurrence of $c_{\perp}$ orientation is relevant for applications of NC PPO films because it markedly increases film transparency as well as guest diffusivity. Surprisingly, we show that the known crystallization procedures lead to $c_{\perp}$ oriented thick $(50-300 \mu \mathrm{m})$ films and to unoriented thin $(\leq 20 \mu \mathrm{m})$ films. This absence of crystalline phase orientation for thin films is rationalized by fast guest sorption kinetics, which avoid co-crystallization in confined spaces and hence inhibit formation of flat-on lamellae. For thick films exhibiting $c_{\perp}$ orientation, sigmoid kinetics of guest sorption and of thickening of PPO films are observed, with inflection points associated with guest-induced film plasticization. Corresponding crystallization kinetics are linear with time and show that co-crystal growth is poorly affected by film plasticization. An additional relevant result of this study is the linear relationship between WAXD crystallinity index and DSC melting enthalpy, which allows evaluation of melting enthalpy of the NC $\alpha$ form of $\operatorname{PPO}\left(\Delta \mathrm{H}_{\mathrm{m}}{ }^{\mathrm{o}}=42 \pm 2 \mathrm{~J} / \mathrm{g}\right)$.
\end{abstract}

Keywords: planar orientation; nanoporous-crystalline films; 2D-WAXD; DSC

\section{Introduction}

Orientation of polymer chain axes ( $c$ axes) in crystalline lamellae are perpendicular or nearly perpendicular (for monoclinic and triclinic unit cells) to the lamellar planes. Crystalline lamellae can be oriented with respect to the polymer film plane, mainly for films having a thickness lower than $1 \mu \mathrm{m}$. Common orientations are the so-called edge-on or flat-on [1-7], which lead to planar orientations of $c$ axes being preferentially parallel or perpendicular to the film plane, respectively.

Even in the absence of mechanical stresses, different kinds of planar orientations [8-14] can be easily achieved for polymer films exhibiting co-crystalline (CC) phases, i.e., where a host polymer includes low-molecular-mass guest molecules in crystalline cavities [15-21]. In fact, even for thickness of several hundredths of microns, different kinds of planar and uniplanar orientations (i.e., preferential orientations of a crystalline axis or of a crystalline plane with respect to the film plane, respectively) have been observed for films exhibiting CC phases of syndiotactic polystyrene [15-17], poly-(L-lactic acid) [18,19] and poly(2,6-dimethyl-1,4-phenylene)oxide (PPO) [20,21].

The kind and degree of planar and uniplanar orientations are relevant for properties of CC polymer phases. In fact, in CC films, the orientation of the host polymer can induce orientation of active guest molecules, being fluorescent [22-25], magnetic [26,27], ferroelectric [28], photo-reactive [29] or chiral-optical [30].

planar and uniplanar orientations of $\mathrm{CC}$ phases are also maintained after guest removal procedures leading the nanoporous-crystalline (NC) phases: $\delta[31,32]$ and $\varepsilon[33,34]$ 
for sPS, $\alpha$ and $\beta$ for PPO [35-37]. This is mainly relevant for guest sorption kinetics because guest diffusivity can be largely changed by proper selection of the orientation of the NC phase [21,38-41]. Maximum diffusivity is generally observed for NC films with orientation of chain axes (and molecular channels) [17] preferentially perpendicular to the film plane $[21,40,41]$. This phenomenon is particularly relevant for NC PPO films with $c_{\perp}$ orientation, which exhibit diffusivities comparable with those of NC powders and not far from those of NC aerogels [40]. As for PPO, it is also worth noting the much higher diffusivity of NC films with respect to amorphous films, although the latter are well known for their high free volume and fast diffusivities [42-49].

NC PPO films with $c_{\perp}$ orientation also have the advantage of transparency comparable with those of amorphous PPO films [50]. This high transparency was rationalized on the basis of the positive birefringence of the polymer and of density and refractive index of the NC phases being lower than those of the corresponding amorphous phase [50]. Hence, PPO films with high guest diffusivity and transparency (both relevant for many possible applications) are achieved by using crystallization procedures leading to $c_{\perp}$ orientation.

For PPO, $c_{\perp}$ orientation was only obtained by slow guest induced crystallization in amorphous films $[21,40,50]$ and was attributed to formation of flat-on crystalline lamellae in nanoconfined layers [51].

In the present paper, for films as obtained by guest (dibenzyl ether)-induced crystallization of amorphous films, we study the dependence of planar orientation on film thickness. The paper also compares kinetics of guest sorption with corresponding kinetics of crystallization and thickness variation of PPO amorphous films.

\section{Materials and Methods}

PPO with $350 \mathrm{~kg} / \mathrm{mol}$ molecular weight (P6130 grade) was supplied by Sabic (Sittard, The Netherlands). Guest molecules: dibenzyl ether (BE) and chloroform $\left(\mathrm{CHCl}_{3}\right)$ were purchased from Aldrich (Milan, Italy).

Amorphous PPO films with different thickness $(\sim 5-300 \mu \mathrm{m})$ were prepared by solution casting in chloroform under fast solvent evaporation conditions (atmospheric pressure and $\mathrm{T} \approx 60^{\circ} \mathrm{C}$ ).

PPO CC films were prepared by guest-induced crystallization of amorphous films. Amorphous PPO films were immersed in liquid BE, at $\sim 20^{\circ} \mathrm{C}$ for immersion time in the range 5-2800 min. For kinetics studies, these CC PPO films just pulled out of BE liquid were immediately quenched in acetonitrile solvent in order to stop further crystallization.

PPO NC films were obtained from PPO CC films by guest extraction with supercritical carbon dioxide $\left(\mathrm{scCO}_{2}\right)$ using SFX 200 equipment (ISCO Inc., Austin, TX, USA) at $\mathrm{P}=250 \mathrm{bar}, \mathrm{T}=40{ }^{\circ} \mathrm{C}$ and with extraction time $\mathrm{t}=4 \mathrm{~h}$. An alternative method of guest extraction, consisting of liquid acetonitrile sorption at room temperature followed by desorption in air again at room temperature, was also used.

Fourier transform infrared (FTIR) spectra were obtained at a $2.0 \mathrm{~cm}^{-1}$ resolution, with a Vertex 70 Bruker FTIR spectrometer (Bruker, Germany).

Differential Scanning Calorimetry (DSC) was conducted in TA Q2000 equipment from TA Instruments (New Castle, DE, USA). The reported DSC scans were conducted on NC PPO films at heating rate of $10^{\circ} \mathrm{C} / \mathrm{min}$ under controlled nitrogen gas flow.

Two-dimensional (2D) wide-angle $X$-ray diffraction (WAXD) patterns were performed in D8 QUEST Bruker diffractometer $\left(\mathrm{CuK}_{\alpha}\right.$ radiation, Bruker, Karlsruhe, Germany) with $\mathrm{X}$-ray beam perpendicular and parallel to the film surface, thus obtaining patterns that are called THROUGH and EDGE, respectively.

Radial profiles were collected (by DIFFRAC.EVA software, Bruker, Karlsruhe, Ger-

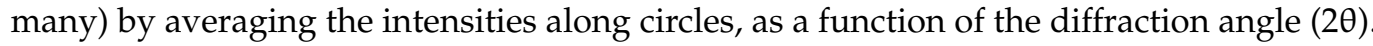
Equatorial and meridional profiles were collected along the equatorial and meridional directions of the collected 2D patterns.

Crystallinity indexes were determined by using radial profiles of 2D WAXD THROUGH patterns. In particular, we have applied the classical method of resolving these patterns 
into two areas corresponding to diffraction halo of the amorphous phase and to diffraction peaks of the crystalline phase, for $3^{\circ}<2 \theta<30^{\circ}$.

The degree of orientation of the chain axes of the crystalline phase $\left(f_{c}\right)$ was evaluated by using the Herman's orientation function:

$$
f_{c}=\left(3 \overline{\cos ^{2} \gamma}-1\right) / 2
$$

where $\cos ^{2} \gamma$ was determined by azimuthal scan of the 001 reflection of the NC $\alpha$ form, at $2 \theta_{\mathrm{CuK} \alpha}=16.8^{\circ}$. In this framework, $f_{c}=0$ corresponds to unoriented crystalline phases, whereas $f_{c}=-0.5$, corresponds to the limit $c_{\perp}$ orientation, where chain axes of all crystallites are perpendicular to the film plane.

\section{Results and Discussion}

\subsection{Dependence of Guest-Induced $c_{\perp}$ Orientation on Film Thickness}

2D-WAXD patterns, as taken with the X-ray beam parallel to the film plane (EDGE patterns), of amorphous PPO films of different thickness in the range 20-300 $\mu \mathrm{m}$, after crystallization induced by equilibrium room-temperature sorption of $\mathrm{BE}$ followed by $\mathrm{BE}$ desorption by $\mathrm{scCO}_{2}$, are shown in Figure 1. As discussed in [36], BE sorption leads to $\mathrm{PPO} / \mathrm{BE}$ co-crystalline form, while the subsequent guest desorption leads to the $\mathrm{NC} \alpha$ form.

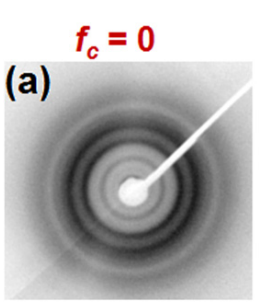

$\sim 20 \mu \mathrm{m}$

$$
f_{c}=-0.21
$$

(b)

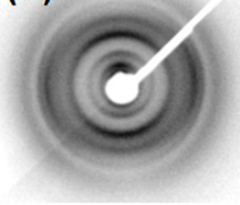

$\sim 50 \mu \mathrm{m}$ $f_{c}=-0.30$

(c)

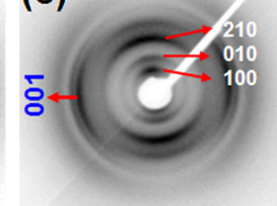

$\sim 150 \mu \mathrm{m}$ $f_{c}=-0.16$

(d)

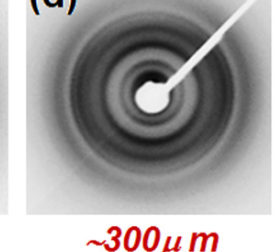

Figure 1. 2D-WAXD EDGE patterns of NC PPO films, as obtained by BE induced crystallization in amorphous films with thickness of: (a) $20 \mu \mathrm{m}$, (b) $\sim 50 \mu \mathrm{m},(\mathbf{c}) \sim 150 \mu \mathrm{m}$ and (d) $\sim 300 \mu \mathrm{m}$, after guest extraction. Degree of orientation $\left(f_{c}\right)$ is indicated at top of the patterns. The 001 reflection arc (centered on the equator) and the main hk0 reflection arcs (centered on the meridian), which show the occurrence of $c_{\perp}$ orientation, are indicated in the pattern (c).

For patterns of thicker films (from $50 \mu \mathrm{m}$ up to $300 \mu \mathrm{m}$, Figure 1b-d), all hk0 reflections are present as arcs centered on the meridian. This clearly indicates, as already described for films of thickness of 50-90 $\mu \mathrm{m}[21,40,50]$, the occurrence of $c_{\perp}$ orientation. Rather surprisingly, the thinner film $(20 \mu \mathrm{m}$, Figure 1a) only exhibits diffraction rings, which clearly indicate absence of crystalline phase orientation.

The degree of orientation $\left(f_{c}\right.$, also indicated on the top of the patterns of Figure 1) is plotted versus thickness of seven starting amorphous PPO films, in Figure 2. For a better understanding of the plot of Figure 2, it is worth citing that the limit degree of $c_{\perp}$ orientation, with all polymer chain axes of crystallites being perfectly perpendicular to the film plane, is $f_{c}=-0.5$. Melting enthalpies of these films are also shown on the right scale in Figure 2. It is apparent that melting enthalpies and hence degrees of crystallinity are poorly dependent on film thickness while, on the contrary, the degree of crystalline phase orientation is maximum for the $150 \mu \mathrm{m}$ film $\left(f_{c}=-0.3\right)$, it is substantially reduced for thicker films (e.g., $f_{c}=-0.16$ for $300 \mu \mathrm{m}$ ) and it is negligible for thickness $\leq 20 \mu \mathrm{m}$.

Results strictly similar to those of Figures 1 and 2 are observed if BE desorption occurs by sorption/desorption of acetonitrile, rather than by $\mathrm{scCO}_{2}$ extraction. 


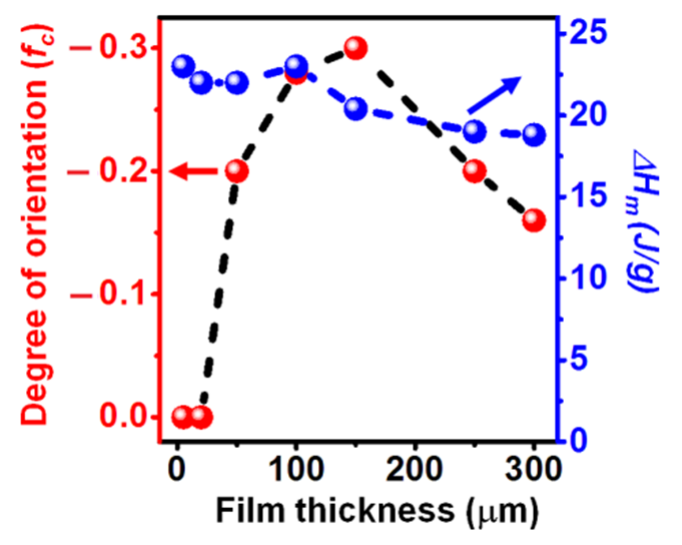

Figure 2. Degree of orientation $\left(f_{c}\right.$, left scale) and melting enthalpy (right scale) of NC PPO films versus thickness of the starting amorphous films. For $f_{\mathcal{c}}=-0.5$, all polymer chain axes of crystallites are perfectly perpendicular to the film plane.

\subsection{Kinetics of Be Guest Sorption from Amorphous Films of Different Thickness}

This rather unexpected absence of crystalline phase orientation in thinner films can be rationalized in the framework of the recently proposed mechanism, for which $c_{\perp}$ orientation is favored by slow uptakes of the guest-inducing polymer co-crystallization [51].

BE sorption kinetics from amorphous PPO films of different thickness, based on the absorbance of the BE FTIR peak at $2215 \mathrm{~cm}^{-1}$, are shown in Figure 3. The kinetics of guest sorption of $5 \mu \mathrm{m}$ and $20 \mu \mathrm{m}$ film are not reported because they are too fast for the used FTIR method. The BE equilibrium uptake for all the PPO films is in the range $70-75 \mathrm{wt} \%$, nearly independently of the thickness of the starting amorphous film, while it is reached in seconds, minutes and hours for $20 \mu \mathrm{m}, 50 \mu \mathrm{m}$ and $150 \mu \mathrm{m}$ films, respectively. The average diffusivity for the kinetics of Figure 3a, as evaluated by the corresponding Fick's plot up to variation of $30 \%$ (Figure $3 \mathrm{~b}$ ), is $\sim 1.3 \pm 0.5 \times 10^{-7} \mathrm{~cm}^{2} \mathrm{sec}^{-1}$.

The absence of orientation for guest-induced crystallization of thin films (Figure 2) is possibly associated with their fast guest sorption kinetics. In the framework of our hypothesis [51], fast guest sorption can avoid co-crystallization in confined spaces and hence formation of flat-on lamellae.

This hypothesis is compatible with SEM images of sections of the NC films. For instance, SEM images of $20 \mu \mathrm{m}$ and $100 \mu \mathrm{m}$ amorphous films, after BE-induced crystallization followed by BE extraction by $\mathrm{scCO}_{2}$ are reported in Figure 4a-d, respectively. The presence of flat-on lamellae for the thicker film (Figure 4d) is apparent, as is the presence of an unoriented fibrillar morphology for the thinner film (Figure $4 b$ ).

\subsection{Kinetics of Guest-Induced Film Thickening and Polymer Crystallization}

Guest uptake in PPO amorphous films induces polymer co-crystallization and leads to remarkable increases (even doubling) of film thickness, which remains essentially unaltered even after complete guest removal).

Kinetics of BE guest sorption (curves a and $a^{\prime}$ ) and kinetics of film thickening (curves $b$ and $b^{\prime}$ ), for films with thickness of $100 \mu \mathrm{m}$ and $150 \mu \mathrm{m}$, are compared in Figure 5A,B, respectively. It is apparent that guest uptake and thickness increase exhibit similar kinetics, with similar sigmoid shapes. 


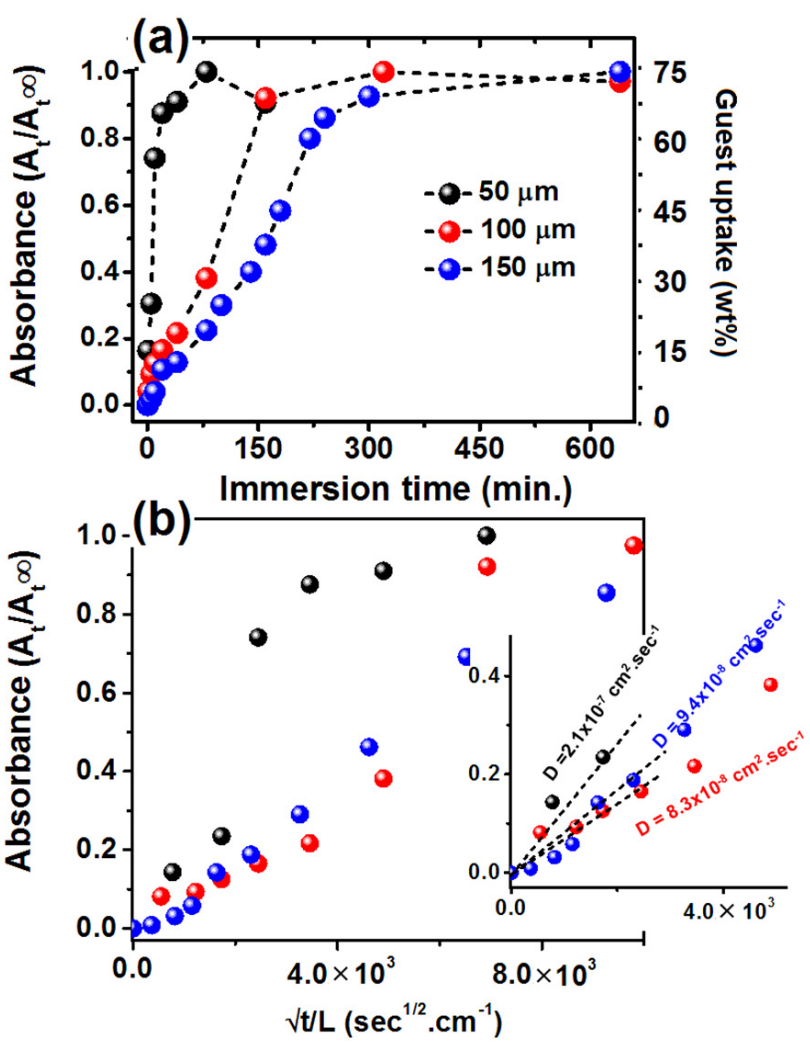

Figure 3. BE guest sorption kinetics at room temperature $\left(\sim 20{ }^{\circ} \mathrm{C}\right)$ in $\mathrm{PPO}$ amorphous films of different thickness (a) and corresponding Fick's plots (b). The weight uptake for the $100 \mu \mathrm{m}$ film is shown on the right scale. The inset in (b) shows enlarged Fick's plot, which have been used to evaluate diffusivity values of BE in amorphous PPO films with different thickness.
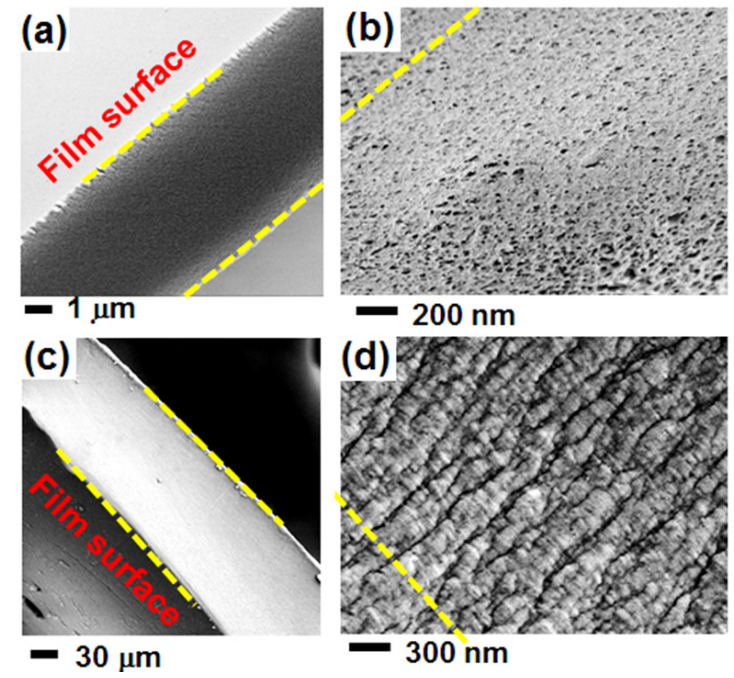

Figure 4. SEM images of sections of NC $\alpha$ form PPO films, as obtained by BE-induced crystallization on amorphous films, followed by BE extraction by $\mathrm{scCO}_{2}$. The thickness of the starting amorphous films is: (a,b) $20 \mu \mathrm{m}$; (c,d) $100 \mu \mathrm{m}$. The presence of flat-on lamellae is apparent only for the thicker film (d). The dashed yellow lines indicate the film surface direction. 


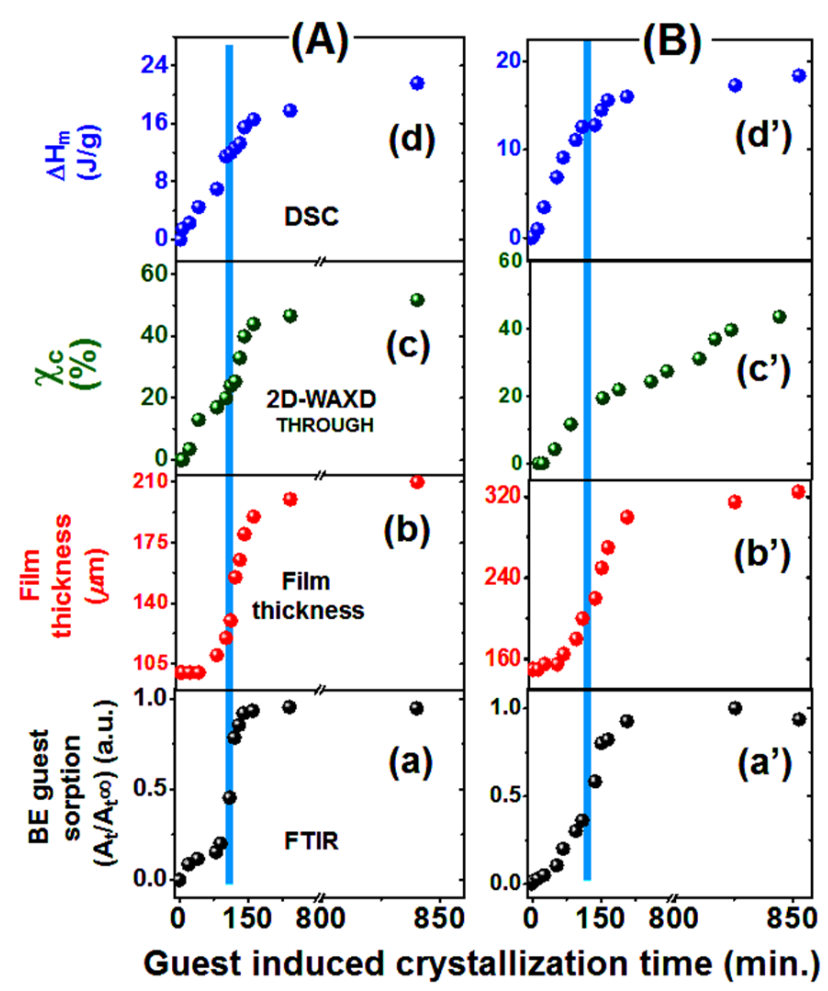

Figure 5. Kinetics of phenomena associated with room-temperature guest-induced crystallization of amorphous PPO films, with thickness of $100 \mu \mathrm{m}$ (A) and $150 \mu \mathrm{m}$ (B): (a, $\left.\mathbf{a}^{\prime}\right)$ BE guest sorption; $\left(\mathbf{b}, \mathbf{b}^{\prime}\right)$ film thickness; $\left(\mathbf{c}, \mathbf{c}^{\prime}\right)$ crystallinity index by WAXD $\left(\chi_{\mathrm{c}}\right) ;\left(\mathbf{d}, \mathbf{d}^{\prime}\right)$ melting enthalpy $\left(\Delta \mathrm{H}_{\mathrm{m}}\right)$. The blue vertical bar indicates the time of inflection of the S-shaped curve describing guest sorption, which can be taken as a measure of the time needed for film plasticization.

This sigmoid behavior is possibly related to the well-known progressive $T_{g}$ reduction as a consequence of sorption of plasticizing molecules in amorphous phases [52]. When, for high guest content, $\mathrm{T}_{\mathrm{g}}$ becomes close to room temperature, the transformation of the glassy phase in a rubbery phase leads to a jump in guest uptake as well as in film thickness.

Kinetics of crystallization as obtained by WAXD and DSC measurements on the NC films are shown as curves $c, c^{\prime}$ and $d, d^{\prime}$ in Figure $5 A, B$, respectively.

2D-WAXD patterns (as taken with the X-ray beam perpendicular to the film plane, THROUGH patterns) of amorphous PPO films, after crystallization induced by BE guest sorption/desorption, only exhibit diffraction rings [21]. Radial diffraction profiles of these 2D-WAXD THROUGH patterns, for a $100 \mu \mathrm{m}$ film, after different sorption times (in the range 20-2800 $\mathrm{min}$ ) are shown in Figure 6a. It is clearly apparent that, as a consequence of sorption, diffraction peaks typical of the NC $\alpha$ form (e.g., 100, 010, 210 and 310) [35,36] appear and progressively increase their intensity. Crystallinity indexes $\left(\chi_{c}\right)$ as evaluated on the basis of the WAXD THROUGH patterns for $100 \mu \mathrm{m}$ and $150 \mu \mathrm{m}$ films are collected in the third column of Tables 1 and 2 and plotted in curves $c$ and $c^{\prime}$ of Figure 5A,B, respectively. 


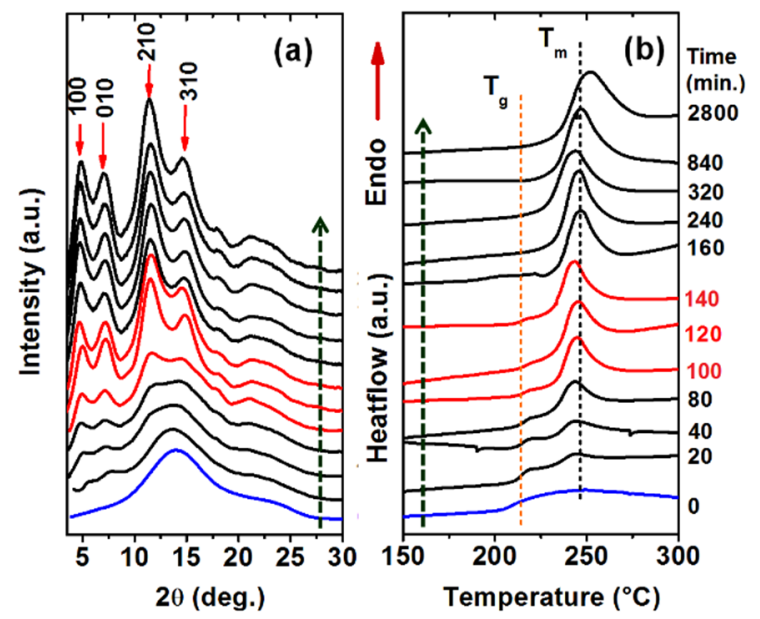

Figure 6. NC $\alpha$ form films, as obtained by sorption/desorption of BE in an amorphous $100 \mu \mathrm{m}$ PPO film for different sorption times: (a) radial profiles of 2D-WAXD THROUGH patterns; (b) DSC scans at h.r. $=10^{\circ} \mathrm{C} / \mathrm{min}$.

Table 1. BE guest sorption at room temperature in amorphous PPO films, with thickness of $\sim 100 \mu \mathrm{m}$, followed by guest removal leading to NC $\alpha$ form: sorption time (min); BE guest uptake $\left(\mathrm{A}_{t} / \mathrm{A}_{t} \infty\right)$; WAXD crystallinity index $(\%)$; melting enthalpy $(\mathrm{J} / \mathrm{g})$; film thickness $(\mu \mathrm{m})$.

\begin{tabular}{|c|c|c|c|c|}
\hline $\begin{array}{c}\text { Sorption } \\
\text { Time (min) }\end{array}$ & $\begin{array}{l}\text { BE Guest Sorption } \\
\left(\mathbf{A}_{t} / \mathbf{A}_{t} \infty\right)\end{array}$ & $\begin{array}{l}\text { Crystallinity Index } \\
\text { WAXD (\%) }( \pm 2)\end{array}$ & $\begin{array}{l}\text { Melting Enthalpy } \\
\left(\Delta \mathrm{H}_{\mathrm{m}}\right) \text { in } \mathrm{J} / \mathrm{g}( \pm \mathbf{0 . 5})\end{array}$ & $\begin{array}{l}\text { Film Thickness } \\
\quad(\mu \mathrm{m})( \pm 4)\end{array}$ \\
\hline 0 & 0 & 0 & 0 & 100 \\
\hline 5 & 0.08 & 0 & 1.5 & 100 \\
\hline 20 & 0.11 & 3.5 & 2.3 & 100 \\
\hline 40 & 0.15 & 13 & 4.5 & 100 \\
\hline 80 & 0.20 & 15 & 7.0 & 110 \\
\hline 100 & 0.45 & 20 & 11.5 & 120 \\
\hline 110 & 0.78 & 29 & 12.0 & 130 \\
\hline 120 & 0.85 & 25 & 12.7 & 155 \\
\hline 130 & 0.91 & 28 & 13.3 & 165 \\
\hline 140 & 0.93 & 38 & 15.5 & 180 \\
\hline 160 & 0.94 & 44 & 16.6 & 190 \\
\hline 240 & 0.95 & 46.6 & 17.8 & 200 \\
\hline 320 & 1 & 48 & 20.3 & 200 \\
\hline 840 & 0.94 & 44 & 21.6 & 210 \\
\hline 2800 & 0.95 & 46 & 22.0 & 210 \\
\hline annealed at $40^{\circ} \mathrm{C}$ & - & 52 & 23.4 & 210 \\
\hline annealed at $60^{\circ} \mathrm{C}$ & - & 60 & 27.1 & 210 \\
\hline
\end{tabular}


Table 2. BE guest sorption at room temperature in amorphous PPO films, with thickness of $\sim 150 \mu$ m, followed by guest removal leading to NC $\alpha$ form: sorption time (min); BE guest uptake $\left(A_{t} / A_{t} \infty\right)$; WAXD crystallinity index (\%); melting enthalpy $(\mathrm{J} / \mathrm{g})$; film thickness $(\mu \mathrm{m})$.

\begin{tabular}{|c|c|c|c|c|}
\hline $\begin{array}{l}\text { Guest Sorption } \\
\text { Time (min) }\end{array}$ & $\begin{array}{c}\text { BE Guest Sorption } \\
\left(\mathbf{A}_{t} / \mathbf{A}_{\mathbf{t}} \infty\right)\end{array}$ & $\begin{array}{l}\text { Crystallinity Index } \\
\text { WAXD (\%) }( \pm 2)\end{array}$ & $\begin{array}{l}\text { Melting Enthalpy } \\
\left(\Delta \mathrm{H}_{\mathrm{m}}\right) \text { in } \mathrm{J} / \mathrm{g}( \pm \mathbf{0 . 5})\end{array}$ & $\begin{array}{l}\text { Film Thickness } \\
\qquad(\mu \mathrm{m})( \pm 4)\end{array}$ \\
\hline 0 & 0 & 0 & 0 & 150 \\
\hline 5 & 0.01 & 0 & 0.2 & 150 \\
\hline 20 & 0.10 & 4.2 & 1.02 & 150 \\
\hline 40 & 0.12 & 11.6 & 3.5 & 155 \\
\hline 80 & 0.22 & 19.4 & 6.9 & 155 \\
\hline 100 & 0.30 & 21.9 & 9.1 & 165 \\
\hline 140 & 0.42 & 24.3 & 11.1 & 180 \\
\hline 160 & 0.48 & 27.4 & 12.6 & 200 \\
\hline 200 & 0.58 & 31.1 & 12.8 & 220 \\
\hline 220 & 0.80 & 36.9 & 14.5 & 250 \\
\hline 240 & 0.86 & 39.6 & 15.6 & 270 \\
\hline 300 & 0.92 & 43.5 & 16 & 300 \\
\hline 640 & 1.0 & 49.8 & 17.3 & 315 \\
\hline 840 & 0.83 & 51 & 18.4 & 325 \\
\hline 1280 & 0.73 & 49.2 & 20 & 345 \\
\hline 2800 & 0.73 & 50.3 & 20.4 & 330 \\
\hline
\end{tabular}

DSC scans of the NC $\alpha$ form films of Figure 6a are shown in Figure 6b. For the amorphous as well as for the poorly crystallized films (corresponding to sorption time $<100 \mathrm{~min}$ ), the PPO glass transition temperature $\left(\mathrm{T}_{\mathrm{g}}\right)$, at nearly $220^{\circ} \mathrm{C}$, is clearly apparent. As the sorption time increases, a melting peak appears, and its area progressively increases up to a melting enthalpy close to $22 \mathrm{~J} / \mathrm{g}$. Melting enthalpies as evaluated for films crystallized after different sorption times for $100 \mu \mathrm{m}$ and $150 \mu \mathrm{m}$ films are collected in the fourth column of Tables 1 and 2 and plotted in curves $d$ and d' of Figure 5A,B, respectively. It is worth noting that for PPO samples, melting enthalpy is an appropriate quantity to evaluate degree of crystallinity, due to the negligible PPO re-crystallization during DSC heating scans [53,54].

For both films with thickness of $100 \mu \mathrm{m}$ and $150 \mu \mathrm{m}$, crystallinity indexes $\left(\chi_{c}\right.$, as evaluated on the basis of the WAXD patterns, like those of Figure 6a) are plotted versus melting enthalpies $\left(\Delta \mathrm{H}_{\mathrm{m}}\right.$, as evaluated by DSC scans, like those of Figure $\left.6 \mathrm{~b}\right)$ in Figure 7. A linear relationship between $\chi_{c}$ and $\Delta H_{m}$ appears, whose extrapolation to $\chi_{c}=100 \%$ allows a rough evaluation of the melting enthalpy of fully crystalline $\alpha$ form PPO samples $\left(\Delta \mathrm{H}_{\mathrm{m}}{ }^{\mathrm{o}}=42 \pm 2 \mathrm{~J} / \mathrm{g}\right)$. To reduce the extrapolation error, two additional points, corresponding to the $100 \mu \mathrm{m}$ film after $2800 \mathrm{~min}$ of BE sorption followed by annealing at $40{ }^{\circ} \mathrm{C}$ and $60{ }^{\circ} \mathrm{C}$ for $12 \mathrm{~h}$ (last two rows of Table 1 ), are added. This $\Delta \mathrm{H}_{\mathrm{m}}{ }^{\mathrm{o}}$ value as obtained by the extrapolation procedure of Figure 7 compares well with the value as determined by measuring the depression of melting temperature in mixtures with chloronaphthalene (42 \pm 8 J/g) [55]. 


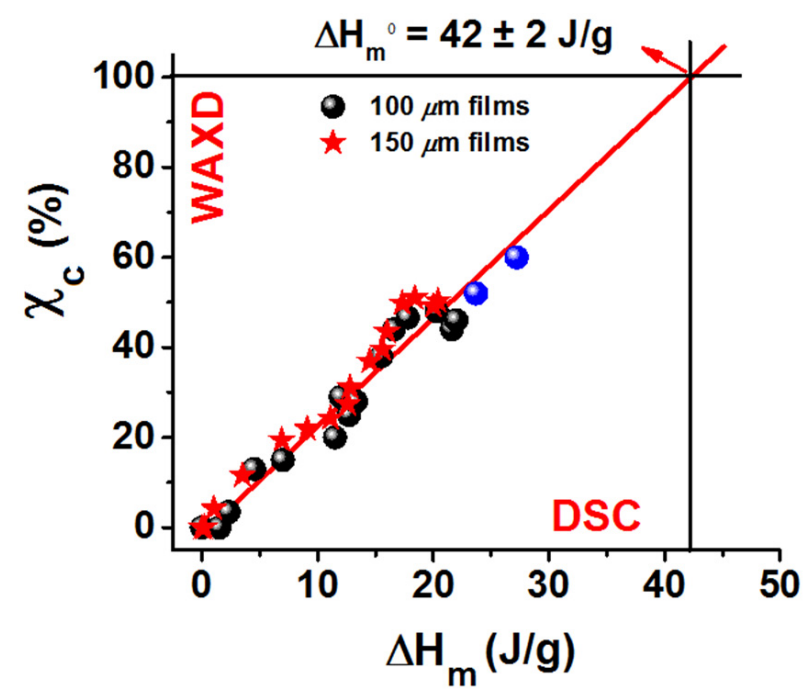

Figure 7. Crystallinity index ( $\chi_{c}$, from WAXD patterns) and melting enthalpy $\left(\Delta \mathrm{H}_{\mathrm{m}}\right.$, from DSC scans) of NC $\alpha$ form films, obtained by BE guest-induced crystallization of amorphous PPO films of different thickness: $(\bullet) 100 \mu \mathrm{m} ;(\star) 150 \mu \mathrm{m}$. The blue circles indicate $100 \mu \mathrm{m}$ films as crystallized after $2800 \mathrm{~min}$ immersion in $\mathrm{BE}$ and subsequently annealed at $40^{\circ} \mathrm{C}$ and $60^{\circ} \mathrm{C}$. The red line indicated the extrapolation to a fully crystalline $\alpha$-form PPO sample.

Plots of Figure 5 show that crystallinity index (plots c) and melting enthalpy (plots d) present similar kinetics, with roughly linear increases before gradual approach to their plateau values, rather than sigmoid increases as observed for guest uptake (plots a) and thickness increase (plots b). This indicates that PPO crystallization, in the co-crystalline form with BE guest, occurs already for low guest concentrations in confined layers imposing formation of flat-on lamellae. By using the terminology of solvent-induced crystallization (often indicated as SINC) of amorphous films [56-61], the kinetics of crystallization is controlled by crystal growth rather than by guest diffusion. Kinetics of crystallization being linear with time indicate that co-crystal growth is poorly affected by film plasticization.

\section{Conclusions}

The planar orientation exhibiting crystalline chain axes preferentially perpendicular to the film plane ( $c_{\perp}$ orientation), which is observed for CC and NC PPO films as obtained by bulky guest (e.g., benzyl ether)-induced crystallization, depends on the thickness of the starting amorphous film. In fact, surprisingly, $c_{\perp}$ orientation occurs only for thick films (50-300 $\mu \mathrm{m})$, while it is not observed for films with thickness lower than or equal to $20 \mu \mathrm{m}$.

This unexpected behavior can be rationalized in the framework of the mechanism of planar oriented crystallization as proposed in a recent paper [51]. In fact, the absence of orientation for guest-induced crystallization of thin films is associated with fast guest sorption, which avoids co-crystallization in confined spaces and hence hinders formation of flat-on lamellae.

Kinetics of guest uptake and film thickening exhibit sigmoid shapes, which are due to the progressive $\mathrm{T}_{\mathrm{g}}$ reduction as a consequence of sorption of plasticizing molecules in amorphous phases [61]. When for high guest content $\mathrm{T}_{\mathrm{g}}$ becomes close to room temperature, the transformation of the glassy phase in a rubbery phase leads to a jump in guest uptake as well as in film thickness.

Crystallization kinetics, as measured by WAXD and DSC techniques, show a completely different behavior with degree of crystallinity increasing linearly with sorption time before approaching their plateau values. This indicates that kinetics of PPO guest-induced co-crystallization, leading for thick films to $c_{\perp}$ orientation, is controlled by crystal growth rather than by guest diffusion. 
An additional relevant result of this study is the linear relationship between WAXD crystallinity index and DSC melting enthalpy, which allows for the evaluation of melting enthalpy of a $100 \% \alpha$ form PPO sample $\left(\Delta \mathrm{H}_{\mathrm{m}}{ }^{\mathrm{o}}=42 \pm 2 \mathrm{~J} / \mathrm{g}\right)$.

Author Contributions: B.N. and G.G.; methodology: B.N. and G.G.; investigation and writing original draft: B.N. and G.G.; Data curation: B.N., C.D., E.V., P.R. and G.G.; supervision and writingreview \& editing: G.G., C.D. and P.R. All authors have read and agreed to the published version of the manuscript.

Funding: B.N. was supported by a research grant from MIUR(PON “R\&I” 2014-2020; ARS01_01398”INPOS”).

Institutional Review Board Statement: Not applicable.

Informed Consent Statement: Not applicable.

Data Availability Statement: The data presented in this study are available on request from the corresponding author.

Acknowledgments: The authors are grateful to Ivano Immediata for technical support and useful discussions.

Conflicts of Interest: The authors declare that there are no conflict of interest regarding the publication of this paper.

\section{References}

1. Wegner, G. Ultrathin films of polymers: Architecture, characterization and properties. Thin Solid Film. 1992, 216, 105-116. [CrossRef]

2. Schonherr, H.; Frank, C.W. Ultrathin films of poly(ethylene oxides) on oxidized silicon. 1. Spectroscopic characterization of film structure and crystallization kinetics. Macromolecules 2003, 36, 1188-1198. [CrossRef]

3. Wang, Y.; Chan, C.M.; Ng, K.M.; Li, L. What Controls the Lamellar Orientation at the Surface of Polymer Films during Crystallization? Macromolecules 2008, 41, 2548-2553. [CrossRef]

4. Yang, P.; Han, Y. Crystal Growth Transition from Flat-On to Edge-On Induced by Solvent Evaporation in Ultrathin Films of Polystyrene- $b$-Poly(ethylene oxide). Langmuir 2009, 25, 9960-9968. [CrossRef]

5. Rueda, D.R.; Hernández, J.J; García-Gutiérrez, M.C.; Ezquerra, T.A.; Soccio, M.; Lotti, N.; Munari, A.; Perlich, J.; Serna, R. Flat-On Lamellae in Spin-Coated, Stable Films of Poly(propylene azelate). Langmuir 2010, 26, 17540-17545. [CrossRef]

6. Chen, M.S.; Niskala, J.R.; Unruh, D.A.; Chu, C.K.; Lee, O.P.; Frechet, J.M.J. Control of Polymer-Packing Orientation in Thin Films through Synthetic Tailoring of Backbone Coplanarity. Chem. Mater. 2013, 25, 4088-4096. [CrossRef]

7. Hu, R.; Pi, Y.; Wang, N.; Zhang, Q.; Feng, J.; Xu, W.; Dong, X.; Wang, D.; Yang, H. The formation of the S-shaped edge-on lamellae on the thin porous polylactic acid membrane via phase separation induced by water microdroplets. J. Appl. Polym. Sci. 2016, 133, 43355. [CrossRef]

8. Heffelfinger, C.J.; Burton, R.L. X-ray determination of the crystallite orientation distributions of poly(ethylene terephthalate) films. J. Polym. Sci. 1960, 47, 289-306. [CrossRef]

9. Pazur, R.J.; Purd'homme, R.E. X-ray Pole Figure and Small Angle Scattering Measurements on Tubular Blown Low-Density Poly(ethylene) Films. Macromolecules 1996, 29, 119-128. [CrossRef]

10. Shibaev, V.; Bobrovsky, A.; Boiko, N. Photoactive liquid crystalline polymer systems with light-controllable structure and optical properties. Progr. Polym. Sci. 2003, 28, 729-836. [CrossRef]

11. Rao, Y.Q.; Greener, J.; Avila-Orta, C.A.; Hsiao, B.S.; Blanton, T.N. The relationship between microstructure and toughness of biaxially oriented semicrystalline polyester films. Polymer 2008, 49, 2507-2514. [CrossRef]

12. Jariyasakoolroj, P.; Tashiro, K.; Hai, W.; Yamamoto, H.; Chinsirikul, W.; Kerddonfag, N.; Chirachanchai, S. Isotropically small crystalline lamellae induced by high biaxial-stretching rate as a key microstructure for super-tough polylactide film. Polymer 2015, 68, 234-245. [CrossRef]

13. Tatsumi, M.; Teramoto, Y.; Nishio, Y. Different orientation patterns of cellulose nanocrystal films prepared from aqueous suspensions by shearing under evaporation. Cellulose 2015, 22, 2983-2992. [CrossRef]

14. Mueller, C.J.; Gann, E.; Singh, C.R.; Thelakkat, M.; McNeill, C.R. Control of Molecular Orientation in Polydiketopyrrolopyrrole Copolymers via Diffusive Noncovalent Interactions. Chem. Mater. 2016, 28, 7088-7097. [CrossRef]

15. Rizzo, P.; Lamberti, M.; Albunia, A.R.; Ruiz de Ballesteros, O.; Guerra, G. Crystalline orientation in syndiotactic polystyrene cast films. Macromolecules 2002, 35, 5854-5860. [CrossRef]

16. Rizzo, P.; Spatola, A.; De Girolamo Del Mauro, A.; Guerra, G. Polymeric Films with Three Different Uniplanar Crystalline Phase Orientations. Macromolecules 2005, 38, 10089-10094. [CrossRef]

17. Albunia, A.R.; Rizzo, P.; Guerra, G. Polymeric Films with Three Different Orientations of Crystalline-Phase Empty Channels. Chem. Mater. 2009, 21, 3370-3375. [CrossRef]

18. Rizzo, P.; Ianniello, G.; Venditto, V.; Tarallo, O.; Guerra, G. Poly(L-lactic acid): Uniplanar Orientation in Cocrystalline Films and Structure of the Cocrystalline Form with Cyclopentanone. Macromolecules 2015, 48, 7513-7520. [CrossRef] 
19. Nagendra, B.; Rizzo, P.; Daniel, C.; Baldino, L.; Guerra, G. c-Perpendicular Orientation of Poly(L-lactide) Films. Polymers 2021, $13,1572$. [CrossRef] [PubMed]

20. Rizzo, P.; Ianniello, G.; Longo, S.; Guerra, G. Uniplanar Orientations and Guest Exchange in PPO Cocrystalline Films. Macromocules 2013, 46, 3995-4001. [CrossRef]

21. Rizzo, P.; Gallo, C.; Vitale, V.; Tarallo, O.; Guerra, G. Nanoporous-crystalline films of PPO with parallel and perpendicular polymer chain orientations. Polymer 2019, 167, 193-201. [CrossRef]

22. Venditto, V.; Milano, G.; De Girolamo Del Mauro, A.; Guerra, G.; Mochizuki, J.; Itagaki, H. Orientation and Microenvironment of Naphthalene Guest in the Host Nanoporous Phase of Syndiotactic Polystyrene. Macromolecules 2005, 38, 3696-3702. [CrossRef]

23. Uda, Y.; Kaneko, F.; Tanigaki, N.; Kawaguchi, T. The First Example of a Polymer-Crystal-Organic-Dye Composite Material: The Clathrate Phase of Syndiotactic Polystyrene with Azulene. Adv. Mater. 2005, 17, 1846-1850. [CrossRef]

24. Itagaki, H.; Sago, T.; Uematsu, M.; Yoshioka, G.; Correa, A.; Venditto, V.; Guerra, G. Guest Orientation in Uniplanar-Axial Polymer Host Films and in Co-Crystal Unit-Cell, Determined by Angular Distributions of Polarized Guest Fluorescence. Macromolecules 2008, 41, 9156-9164. [CrossRef]

25. Sano, T.; Uchiyama, A.; Sago, T.; Itagaki, H. Fluorescence behavior of syndiotactic polystyrene and its derivative: Formation of a ground-state dimer in the solid state. Eur. Polym. 2017, 90, 114-121. [CrossRef]

26. Kaneko, F.; Uda, Y.; Kajiwara, A.; Tanigaki, N. Molecular-Complex Formation of Syndiotactic Polystyrene with Stable Radical Molecules. Macromol. Rapid Commun. 2006, 27, 1643-1647. [CrossRef]

27. Albunia, A.R.; D'Aniello, C.; Guerra, G.; Gatteschi, D.; Mannini, M.; Sorace, L. Ordering Magnetic Molecules within Nanoporous Crystalline Polymers. Chem. Mater. 2009, 21, 4750-4752. [CrossRef]

28. Daniel, C.; Rufolo, C.; Bobba, F.; Scarfato, A.; Cucolo, A.; Guerra, G. Ferroelectric co-crystalline polymers. J. Mater. Chem. 2011, 21, 19074-19079. [CrossRef]

29. Stegmaier, P.; De Girolamo Del Mauro, A.; Venditto, V.; Guerra, G. Optical recording materials based on photoisomerization of guest molecules of a polymeric crystalline host phase. Adv. Mater. 2005, 17, 1166-1168. [CrossRef]

30. Rizzo, P.; Abbate, S.; Longhi, G.; Guerra, G. Circularly polarized luminescence of syndiotactic polystyrene. Opt. Mater. 2017, 73, 595-601. [CrossRef]

31. De Rosa, C.; Guerra, G.; Petraccone, V.; Pirozzi, B. Crystal structure of the emptied clathrate form (*e form) of syndiotactic polystyrene. Macromolecules 1997, 30,4147-4152. [CrossRef]

32. Bhoje Gowd, E.; Shibayama, N.; Tashiro, K. Structural Changes in Thermally Induced Phase Transitions of Uniaxially Oriented $\delta_{\mathrm{e}}$ Form of Syndiotactic Polystyrene Investigated by Temperature-Dependent Measurements of X-ray Fiber Diagrams and Polarized Infrared Spectra. Macromolecules 2006, 39, 8412-8418. [CrossRef]

33. Petraccone, V.; Ruiz de Ballesteros, O.; Tarallo, O.; Rizzo, P.; Guerra, G. Nanoporous Polymer Crystals with Cavities and Channels. Chem. Mater. 2008, 20, 3663-3668. [CrossRef]

34. Itagaki, H.; Sano, T.; Okabe, T.; Sano, S.; Ebihara, H.; Tomono, F.; Dohra, H. Polymerization of Aniline in Tubular Cavities of the Crystalline Phase of Syndiotactic Polystyrene: Proposal of a Preparation Method of Sophisticated Polymer Composites. ACS Macro Lett. 2017, 6, 1099-1103. [CrossRef]

35. Daniel, C.; Longo, S.; Fasano, G.; Vitillo, J.G.; Guerra, G. Nanoporous Crystalline Phases of Poly(2,6-Dimethyl-1,4-phenylene)oxide. Chem. Mater. 2011, 23, 3195-3200. [CrossRef]

36. Nagendra, B.; Cozzolino, A.; Daniel, C.; Rizzo, P.; Guerra, G.; Auriemma, F.; De Rosa, C.; D'Alterio, M.C.; Tarallo, O.; Nuzzo, A. Two nanoporous-crystalline forms of PPO and related co-crystalline forms. Macromolecules 2019, 52, 9646-9656. [CrossRef]

37. Yu, A.; Alentiev, I.S.; Levin, M.I.; Buzin, N.A.; Belov, R.Y.; Nikiforov, S.V.; Chirkov, I.V.; Blagodatskikh, A.S.; Kechekyan, P.A.; Kechekyan, V.G.; et al. Gas transport parameters, density and free volume of nanocrystalline poly-2,6-dimethylphenylene oxide. Polymer 2021, 226, 123804. [CrossRef]

38. Venditto, V.; De Girolamo Del Mauro, A.; Mensitieri, G.; Milano, G.; Musto, P.; Rizzo, P.; Guerra, G. Anisotropic Guest Diffusion in the $\delta$ Crystalline Host Phase of Syndiotactic Polystyrene: Transport Kinetics in Films with Three Different Uniplanar Orientations of the Host Phase. Chem. Mater. 2006, 18, 2205-2210. [CrossRef]

39. Albunia, A.R.; Rizzo, P.; Guerra, G. Control of guest transport in polymer films by structure and orientation of nanoporouscrystalline phases. Polymers 2013, 54, 1671-1678. [CrossRef]

40. Daniel, C.; Rizzo, P.; Nagendra, B.; Cozzolino, A.; Guerra, G. High guest diffusivity of PPO films with perpendicular orientation of chain axes of nanoporous-crystalline phases. Polymer 2021, 229, 124005. [CrossRef]

41. Cozzolino, A.; Nagendra, B.; Rizzo, P.; Daniel, C.; Guerra, G. Fast uptake of organic pollutants from dilute aqueous solutions by nanoporous-crystalline PPO films with c-perpendicular orientation. J. Eur. Polym. 2021, 161, 110864. [CrossRef]

42. Alentiev, A.; Drioli, E.; Gokzhaev, M.; Golemme, G.; Ilinich, O.; Lapkin, A.; Volkov, V.; Yampolskii, Y. Gas permeation properties of phenylene oxide polymers. J. Membr. Sci. 1998, 138, 99-107. [CrossRef]

43. Chowdhury, G.; Vujosevic, R.; Matsuura, T.; Laverty, B. Effects of polymer molecular weight and chemical modification on the gas transport properties of poly(2,6-dimethyl-1,4-phenylene oxide). J. Appl. Polym. Sci. 2000, 77, 1137-1143. [CrossRef]

44. Tsujita, Y. Gas sorption and permeation of glassy polymers with microvoids. Prog. Polym. Sci. 2003, 28, 1377-1401. [CrossRef]

45. Huang, Y.; Paul, D.R. Physical aging of thin glassy polymer films monitored by gas permeability. Polymer 2004, 45, 8377-8393. [CrossRef]

46. Huang, Y.; Wang, X.; Paul, D.R. Physical aging of thin glassy polymer films: Free volume interpretation. J. Membr. Sci. 2006, 277, 219-229. [CrossRef] 
47. Horn, N.R.; Paul, D.R. Carbon Dioxide Sorption and Plasticization of Thin Glassy Polymer Films Tracked by Optical Methods. Macromolecules 2012, 45, 2820-2834. [CrossRef]

48. Minelli, M.; De Angelis, M.G.; Sarti, G.C. Predictive calculations of gas solubility and permeability in glassy polymeric membranes: An overview. Front. Chem. Sci. Eng. 2017, 11, 405-413. [CrossRef]

49. Soniat, M.; Tesfaye, M.; Mafi, A.; Brooks, D.J.; Humphrey, N.D.; Weng, L.-C.; Merinov, B.; Goddard, W.A., III; Weber, A.Z.; Houle, F.A. Permeation of CO2 and N2 through glassy poly(dimethyl phenylene) oxide under steady-and presteady-state conditions. J. Polym. Sci. 2020, 58, 1207-1228. [CrossRef]

50. Nagendra, B.; Rizzo, P.; Daniel, C.; Guerra, G. Planar Orientation and Transparency of Nanoporous-Crystalline Polymer Films. Macromolecules 2021, 54, 6605-6611. [CrossRef]

51. Nagendra, B.; Golla, M.; Gallo, C.; Daniel, C.; Rizzo, P.; Guerra, G.; Baldino, L.; Reverchon, E. Mechanisms Determining Different Planar Orientations in PPO Films Crystallized by Guest Sorption. Polymer 2021, 235, 124242. [CrossRef]

52. Musto, P.; Loianno, V.; Scherillo, G.; La Manna, P.; Galizia, M.; Guerra, G.; Mensitieri, G. Benzene-Induced Crystallization of PPO: A Combined Thermodynamic and Vibrational Spectroscopy Study. Ind. Eng. Chem. Res. 2020, 59, 5402-5411. [CrossRef]

53. Daniel, C.; Zhovner, D.; Guerra, G. Thermal Stability of Nanoporous Crystalline and Amorphous Phases of Poly(2,6-dimethyl-1,4phenylene) Oxide. Macromolecules 2013, 46, 449-454. [CrossRef]

54. Nagendra, B.; Golla, M.; Daniel, C.; Rizzo, P.; Guerra, G. Melting of nanoporous-crystalline and co-crystalline solution cast films of poly(2,6-dimethyl-1,4-phenylene) oxide. Polymer 2021, 228, 123935. [CrossRef]

55. Karasz, F.E.; Bair, H.E.; O’Reilly, J.M. Thermodynamic properties of poly(2,6-dimethyl-1,4-phenylene ether). J. Polym. Sci. Polym. Phys. Ed. 1968, 6, 1141-1148. [CrossRef]

56. Turska, E.; Benecki, W. Studies of liquid-induced crystallization of bisphenol A polycarbonate. J. Appl. Polym. Sci. 1979, 23, 3489-3500. [CrossRef]

57. Durning, C.J.; Russel, W.B. A mathematical model for diffusion with induced crystallization: 2. Polymer 1985, 26, 131-140. [CrossRef]

58. Waywood, W.J.; Durning, C.J. Solvent-induced crystallization of a compatible polymer blend. Polym. Eng. Sci. 1987, 27, 1265-1274. [CrossRef]

59. Ouyang, H.; Lee, W.-H.; Shiue, S.-T.; Lin, T.-L. Solvent-induced crystallization in poly(ethylene terephthalate) during mass transport. J. Polym. Sci. Part B Polym. Phys. 2002, 40, 1444-1453. [CrossRef]

60. Tashiro, K.; Yoshioka, A. Molecular mechanism of solvent-induced crystallization of syndiotactic polystyrene glass. 2. Detection of enhanced motion of the amorphous chains in the induction period of crystallization. Macromolecules 2002, 35, 410-414. [CrossRef]

61. Gupper, A.; Chan, K.L.A.; Kazarian, S.G. FT-IR imaging of solvent-indiced crystallization in polymers. Macromolecules 2004, 37, 6498-6503. [CrossRef] 